\title{
A Novel Polysaccharide Isolated From Fresh Longan (Dimocarpus longan Lour.) Activates Macrophage via TLR2/4-Mediated PI3/AKT and MyD88/TRAF6 Pathways
}

\author{
Haibo Lan ${ }^{1,2,3 \dagger}, W u L^{1 * t}$, Jucai Xu ${ }^{1}$, Yuzhe Yang ${ }^{2}$, Zhaolun $\operatorname{Tan}^{2}$ and Ruili Yang ${ }^{2 *}$ \\ ${ }^{1}$ School of Biotechnology and Health Sciences, Wuyi University, Jiangmen, China, ${ }^{2}$ College of Food Science, South China \\ Agricultural University, Guangzhou, China, ${ }^{3}$ School of Biotechnology, Sichuan University of Science \& Engineering, Yibin, China
}

OPEN ACCESS

Edited by:

Haibin Tong,

Wenzhou University, China

Reviewed by:

Ningyang $L i$

Shandong Agricultural University,

China

Wang Lingchong,

Nanjing University of Chinese

Medicine, China

${ }^{*}$ Correspondence:

Wu Li

leewuu@163.com

Ruili Yang

rlyang77@scau.edu.cn

${ }^{\dagger}$ These authors have contributed equally to this work

Specialty section: This article was submitted to Ethnopharmacology,

a section of the journal

Frontiers in Pharmacology

Received: 29 September 2021 Accepted: 18 November 2021 Published: 21 December 2021

Citation:

Lan H, Li W, Xu J, Yang Y, Tan Z and Yang R (2021) A Novel Polysaccharide Isolated From Fresh Longan (Dimocarpus longan Lour.) Activates Macrophage via TLR2/4-Mediated

PI3/AKT and MyD88/ TRAF6 Pathways.

Front. Pharmacol. 12:786127. doi: 10.3389/fphar.2021.786127
A novel immunomodulatory polysaccharide (LP4) with a molecular weight $6.31 \times$ $10^{4} \mathrm{~g} / \mathrm{mol}$ was purified from fresh longan pulp. It was composed of mannose, glucose, glucuronic acid, galactose, xylose, arabinose, galacturonic acid, fucose, and rhamnose in a molar percentage of $36: 31: 10: 7: 4: 4: 3: 2: 2$, and mainly linked by $(1 \rightarrow 6)-\beta$-Man, $(1 \rightarrow 4)-\beta$-Glc and $(1 \rightarrow 6)-\alpha$-Glc. LP4 can obviously enhance the phagocytosis of macrophages and promote the proliferation of lymphocytes. After treating macrophages with LP4 $(12.5-50 \mu \mathrm{g} / \mathrm{ml})$, the production of IL-1 $\beta$ and TNF- $\alpha$ was significantly increased. These increases of cytokines were suppressed when the TLR2/TLR4 receptors were inhibited by anti-TLR2 and/or anti-TLR4 antibodies. Moreover, the mRNA expression of INOS, AKT, PI3K, TRAF6 and MyD88 was significantly suppressed by TLR2/TLR4 antibodies. These results indicated that LP4 induced macrophage activation mainly via the TLR2 and TLR4-induced PI3K/ AKT and MyD88/TRAF6 pathways.

Keywords: biomacromolecules, polysaccharide, longan, toll-like receptors, PI3K/Akt pathway

\section{INTRODUCTION}

Polysaccharides, a kind of bio-macromolecule which are widely distributed in animals, plants and microorganisms, were extensively involved in cell proliferation, differentiation and signal transduction (Xie et al., 2016). A number of pharmacological activities of natural polysaccharides have been reported, such as antiviral, antitumor, and immunomodulatory activities (He et al., 2020; López-Legarda et al., 2020). Recently, several natural polysaccharides such as Ganoderma polysaccharide, Astragalus polysaccharide and Lentinan polysaccharide are used for clinical treatment of cancer in combination with chemotherapy (Yu et al., 2018; Lin and Sun, 2019). Although polysaccharides from various natural sources have been displayed significant biological activities, the application of many natural polysaccharides in medicine and functional foods are limited due to the unclear of composition and structure (Wang et al., 2018b).

Longan (Dimocarpus longan Lour.) is a well-known 'Medicinal and Edible' fruit in China and Southeastern Asia. Longan was used to improve the immunity and treat disease such as palpitation, amnesia, neurasthenia, and relieving fatigue (Zhang et al., 2017). Recent researches showed that longan polysaccharides have a various bioactivities, including antioxidative (Yang et al., 2011), 
antitumor (Meng et al., 2014) immunoregulatory activities (Yi et al., 2015; Zhang et al., 2017; Rong et al., 2019), regulating intestinal flora and intestinal metabolites (Zhang et al., 2017; Bai et al., 2020).

In previous studies, several active polysaccharides have been isolated from longan. However, there are differences in the structural characteristics of longan polysaccharides in these previous reports. An active polysaccharide isolated from longan composed of $\rightarrow 6$ )-Glc- $(1 \rightarrow, \rightarrow 5)$-Ara-( $(1 \rightarrow, \rightarrow 4)$-Man$(1 \rightarrow$ and $\rightarrow 6)$-Gal-( $(1 \rightarrow$ can increase the inducible nitric oxide synthase activity, TNF- $\alpha$ and IL- 6 secretion of macrophages (Yi et al., 2015). A longan polysaccharide obtained by Meng et al. (2014), which composed of glucose, arabinose, galactose and galacturonic acid, stimulated the production of IFN- $\gamma$ and increased the phagocytic ability of macrophages. Zhu et al. (2013) obtained a homogeneous active polysaccharide from longan composed of $(1 \rightarrow 6)$ - $\alpha$-glucan. In early research (Rong et al., 2019), we purified an active polysaccharide (LPD2) from longan, which composed of $(1 \rightarrow 4)-\beta$-Glc with substituted by acetyl, and $(1 \rightarrow 6)-\beta$-Man, and induced macrophage activation via the TLR2-and TLR4-mediated MyD88/IRAK4-TRAF6 pathways. The differences in the structure of polysaccharides in these reports may be due to different extraction methods or drying processes (Gan et al., 2021). However, there may be multiple polysaccharides in longan that contribute to the bioactivity of longan. The study on the composition and structure of longan active polysaccharides may help to clarify their principal active components and furtherly apply in medicine.

In this study, a novel polysaccharide (LP4) was purified from fresh longan. The structure of LP4 was characterized and its immune regulation activity was evaluated. Present study will contribute to reveal the active polysaccharide composition and potential mechanism of immunoregulation of longan polysaccharide.

\section{MATERIALS AND METHODS}

\section{Materials}

Longan fruit (cv. Chuliang) was obtained from a local orchard (Gaozhou, Guangdong province, China) which was harvested at maturity stage in 2016. The RAW264.7 cells were purchased from Cell Bank of Chinese Academic of Science (Shanghai, China). DMEM medium, RPMI-1640 medium, fetal bovine serum, AntiTLR2 (6C2) and Anti-TLR4 (MTS510) antibodies were purchased from Thermo Fisher Scientific (Waltham, MA, United States). Polymyxin B, neutral red and lipopolysaccharide (LPS) were purchased from Sigma-Aldrich (Shanghai, China).

\section{Extraction and Purification of Polysaccharides}

The longan fruit were peeled, stoned and homogenized using a homogenizer ( $30 s \times 2$, C91T, Joyang Co., Ltd., Jinan, China). The homogenates were extracted with distilled water at $80^{\circ} \mathrm{C}$ for $3 \mathrm{~h}$. The extracts were filtrated with gauze $(74 \mu \mathrm{m})$ and then centrifuged $(3,000 \mathrm{~g} / \mathrm{min})$ for $20 \mathrm{~min}$. The liquid supernatant was concentrated to $1 / 10$ the original volume by rotary evaporation at $55^{\circ} \mathrm{C}$ and then discarded protein and pigment by D301R resin (Tianjin Bohong Resin Co., Ltd., Tianjin, China) using our previous method (Yi et al., 2012). After centrifuging, the filtrates were dialyzed $(8,000-14,000 \mathrm{Da}) 3$ days in distilled water to remove small molecule compounds. A crude longan polysaccharide was collected via freeze-drying. The crude polysaccharide $(10 \mathrm{mg} / \mathrm{ml})$ was fractionated with a DEAE-fast flow column $(2.0 \mathrm{~cm} \times 30 \mathrm{~cm})$, which was eluted with different concentrations of sodium chloride $(0,0.02,0.05,0.1 \mathrm{~mol} / \mathrm{L})$. The eluate $(3.0 \mathrm{ml} /$ tube) was monitored via the phenol-sulfuric acid method at $490 \mathrm{~nm}$ to find out the polysaccharide components (Masuko et al., 2005). The eluting profiles is shown in Supplementary Figure S1. The eluted fractions (eluted by $0.05 \mathrm{~mol} / \mathrm{L} \mathrm{NaCl}$ ) were further purified on a liquid chromatography system (Agilent 1200, refractive index detector, Santa Clara, CA, United States) with TSKgel-G3000PW $\mathrm{XL}_{\mathrm{XL}}$ in series

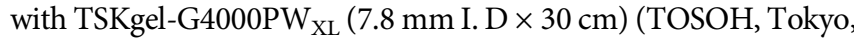
Japan) columns. The sample was eluted with $0.6 \mathrm{ml} / \mathrm{min}$ water at $55^{\circ} \mathrm{C}$. The main fraction peaks (LP4) were collected in the light of the retention time and peaks. This samples were collected and lyophilized.

\section{Structural Analysis of LP4 SEC-MALLS}

The molecular features of LP4 were confirmed with highperformance size exclusion chromatography (Waters 2695, Milford, MA, United States) coupled with a multi-angle laser light scattering detector (DAWN HELEOS-II, Wyatt Technology, Santa Barbara, CA, United States) and refractive index detector (Optilab DSP, Wyatt Technology, Santa Barbara, CA, United States) (SEC-MALLS-RID). LP4 was analyzed on a Ultrahydrogel 2000 (Waters, Milford, MA, United States) column and eluted with $0.1 \mathrm{~mol} / \mathrm{L} \mathrm{NaNO}_{3}(0.5 \mathrm{ml} / \mathrm{min})$. The column temperature was kept at $35^{\circ} \mathrm{C}$. The data were analyzed with ASTRA 5.3.4.20 software.

\section{Monosaccharide Composition}

The monosaccharide composition was analyzed according to previously published method (Wang et al., 2017). Briefly, the sample $(10.0 \mathrm{mg})$ was completely hydrolyzed in $2 \mathrm{ml}$ trifluoroacetic acid $(2.0 \mathrm{~mol} / \mathrm{L})$ at $121^{\circ} \mathrm{C}$ for $2 \mathrm{~h}$. After adjusting $\mathrm{pH}=7.0, \mathrm{NaCO}_{3}(0.5 \mathrm{~mol} / \mathrm{L}, 80 \mu \mathrm{L})$ was added and incubated for $45 \mathrm{~min}$ at $30^{\circ} \mathrm{C}$. Thereafter $50.0 \mathrm{mg} \mathrm{NaBH} 4(4 \%$, $\mathrm{w} / \mathrm{v}$ ) was added and maintained at room temperature for $2 \mathrm{~h}$. The remaining reagent was neutralized by $25 \%(\mathrm{v} / \mathrm{v})$ glacial acetic acid. Cation exchange column was used to remove $\mathrm{Na}^{+}$and boric acid was washed off with methyl alcohol. After that, the residue was place in a vacuum drying oven for $2 \mathrm{~h}$ at $85^{\circ} \mathrm{C}$ to convert the uronic acid salt as lactone. In the end, pyridine $(1 \mathrm{ml})$ and normal propyl amine $(1 \mathrm{ml})$ were added for $30 \mathrm{~min}$ at $55^{\circ} \mathrm{C}$. After drying, the residue was dissolved in $1 \mathrm{ml}$ pyridine and $1 \mathrm{ml}$ acetic anhydride at $100^{\circ} \mathrm{C}$ for $1 \mathrm{~h}$. After evaporation drying the sample was dissolved in $2 \mathrm{ml} \mathrm{CH}_{2} \mathrm{Cl}_{2}$ and filtered $(0.45 \mu \mathrm{m}$ pore size), then was analyzed using GC. The injection temperature was $180^{\circ} \mathrm{C}$ and kept for $3 \mathrm{~min}$, then went up to 


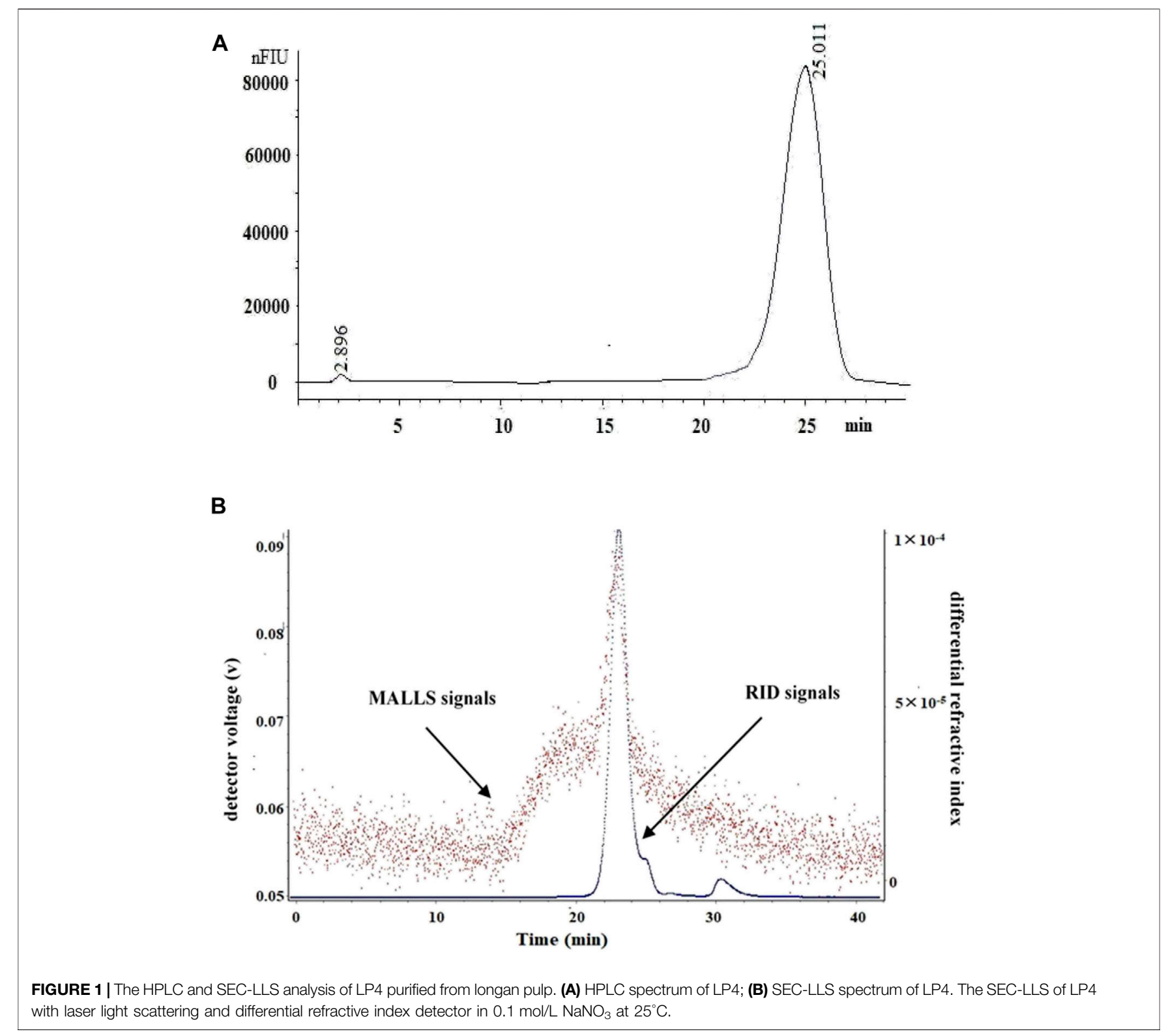

TABLE 1 | The molecular weight and size of LP4.

\begin{tabular}{|c|c|c|c|c|c|c|}
\hline \multicolumn{4}{|c|}{ Molar mass moments $(\mathrm{g} / \mathrm{mol})$} & \multicolumn{3}{|c|}{ Rms radius moments $(\mathrm{nm})$} \\
\hline Mn & Mw & Mz & Mp & $\mathbf{R n}$ & Rw & $\mathbf{R z}$ \\
\hline $\begin{array}{l}3.58 \times 10^{4} \\
M w / M n=1.76\end{array}$ & $6.31 \times 10^{4}$ & $\begin{array}{l}2.25 \times 10^{5} \\
\mathrm{Mz} / \mathrm{Mn}=6.29\end{array}$ & $2.87 \times 10^{4}$ & 56.32 & 70.13 & 100.65 \\
\hline
\end{tabular}

$210^{\circ} \mathrm{C}$ by $0.3^{\circ} \mathrm{C} / \mathrm{min}$ and finally increased to $240^{\circ} \mathrm{C}$ and held for $30 \mathrm{~min}$. The carrier gas was $\mathrm{N}_{2}$ with the rate of $0.88 \mathrm{ml} / \mathrm{min}$. The split ratio was 19:1 and the pressure was $110 \mathrm{kPa}$.

\section{GC-MS}

The methylation analysis of LP4 was conducted according to the previously published method (Needs and Selvendran, 1993; Rong et al., 2019). Briefly, $8.0 \mathrm{mg}$ samples and $200 \mathrm{mg} \mathrm{NaOH}$ were dissolved in $5.0 \mathrm{ml}$ anhydrous dimethyl sulfoxide and stirred for $4 \mathrm{~h}$. Then $1.5 \mathrm{ml}$ methyl iodide were added and light-tight reaction for $2 \mathrm{~h}$. This chemical reaction was terminated by adding $4.0 \mathrm{ml}$ of distilled water and extracted with $3.0 \mathrm{ml}$ $\mathrm{CHCl}_{3}$. The samples was dried with a rotary evaporation and then hydrolyzed by trifluoroacetic acid and acetylation with acetic 
TABLE 2 | The relative molar percentage of glycosidic linkages in LP4.

\begin{tabular}{lcc} 
Composition & Glycosidic linkages & $\begin{array}{c}\text { Relative } \\
\text { molar percentage (\%) }\end{array}$ \\
\hline Mannose & $\rightarrow 6)$-Man- $(1 \rightarrow$ & 41.41 \\
Glucose & $\rightarrow 6)-$ Glc- $(1 \rightarrow$ & 15.95 \\
& $\rightarrow 4)-$ Glc- $(1 \rightarrow$ & 15.27 \\
Galactose & Glc- $(1 \rightarrow$ & 5.21 \\
& $\rightarrow 4)-$ Gal- $(1 \rightarrow$ & 6.97 \\
Xylose & Gal- $(1 \rightarrow$ & 3.21 \\
Arabinose & $\rightarrow 4)-$ Xyl- $(1 \rightarrow$ & 4.36 \\
& $\rightarrow 5)-$ Ara- $(1 \rightarrow$ & 2.10 \\
Fucose & $\rightarrow 3)-$ Ara- $(1 \rightarrow$ & 1.72 \\
Rhamnose & $\rightarrow 4)-$ Fuc- $(1 \rightarrow$ & 2.17 \\
& $\rightarrow 2)$-Rha- $(1 \rightarrow$ & 1.62
\end{tabular}

anhydride and pyridine. At last, the samples were extracted with $\mathrm{CHCl}_{3}$ and analyzed by GC-MS (Agilent 7890-5977, Agilent, Santa Clara, CA, United States) equipped with an DB-225 column (J\&W Scientific, Folsom, CA, United States). The operation conditions were set as follows: the initial column temperature was $55^{\circ} \mathrm{C}$ for $0.75 \mathrm{~min}$, increased to $140^{\circ} \mathrm{C}$ at $45^{\circ} \mathrm{C} / \mathrm{min}$. After keeping $1 \mathrm{~min}$, the temperature was raised to $218^{\circ} \mathrm{C}$ with a rate of $2.5^{\circ} \mathrm{C} / \mathrm{min}$ and keeping for $37 \mathrm{~min}$. Linear velocity of the carrier gas $\left(\mathrm{H}_{2}\right)$ was set at $50 \mathrm{~cm} / \mathrm{s}$ at $218^{\circ} \mathrm{C}$. The mass spectrometer was operated in the electron impact mode (EI) at $70 \mathrm{eV}$ scanning the range $50-700 \mathrm{~m} / \mathrm{z}$, in a full scan acquisition mode.

\section{FT-IR Analysis}

The infrared spectral characteristics of LP4 was characterized by infrared spectrophotometer (TENSOR27, Bruker, Karlsruhe, Germany). LP4 (1.0 mg) was ground with $\mathrm{KBr}$ powder before pressed into pellets, then measured by IR spectral in the range of $4,000-400 \mathrm{~cm}^{-1}$.

\section{NMR Analysis}

LP4 (20.0 mg) was completely dissolved in $0.8 \mathrm{ml} \mathrm{D}_{2} \mathrm{O}$ and then transferred into NMR-tube. ${ }^{1} \mathrm{H}$ and ${ }^{13} \mathrm{C}$ NMR and 2D (COSY and HSQC) spectra were recorded using a $400 \mathrm{MHz}$ spectrometer (Bruker, Karlsruhe, German) operating at $30^{\circ} \mathrm{C}$.

\section{Evaluation of the Immunoregulation Activities of LP4}

\section{Phagocytosis Assay}

Macrophages phagocytic capacity was referred to a previously method (Weeks et al., 1987; Long et al., 2005). Briefly, RAW 264.7 cells $\left(2 \times 10^{5}\right.$ cells $\left./ \mathrm{mL}\right)$ were plated into a 96 -well plate incubated for $3 \mathrm{~h}$. Then LP4 were treated with 1,000 units/mL polymyxin $B$ (PMB) for $60 \mathrm{~min}$ to exclude the effect of lipopolysaccharide (LPS). After LP4 (final concentration: $0,12.5,25$ and $50 \mu \mathrm{g} / \mathrm{ml}$ ) was added for $24 \mathrm{~h}$, the phagocytosis was assessed with $100 \mu \mathrm{L}$ neutral red $(0.1 \%, \mathrm{w} / \mathrm{v})$ incubated for $4 \mathrm{~h}$. Then, the plate was washed with medium, and a $200 \mu \mathrm{L}$ cell lysate (1:1 acetic acid to ethanol (v/v) was added and incubated for $1 \mathrm{~h}$. The absorbance at $570 \mathrm{~nm}$ was measured with a microplate reader. The phagocytic index was calculated as the relative increase of absorbance value of each sample in relation to the control.

\section{TNF- $\alpha$ and IL-1 $\beta$ Assay}

The RAW264.7 cells $\left(2 \times 10^{5}\right.$ cells $\left./ \mathrm{mL}\right)$ were seeded into 96 -well plates and cultured in DMEM medium at $37^{\circ} \mathrm{C}$ under $5 \% \mathrm{CO}_{2}$. After incubation for $4 \mathrm{~h}$, the plates were washed twice by DMEM medium and $200 \mu \mathrm{L}$ medium with LP4 $(0,12.5,25$ and $50 \mu \mathrm{g} / \mathrm{ml})$ was added to the wells, followed by incubation for $24 \mathrm{~h}$. The cells cultured in DMEM without LP4 were used as the control group. The levels of TNF- $\alpha$ and IL- $1 \beta$ were measured using the ELISA kits (R\&D systems, Minneapolis, MN, United States), respectively. The level was normalized and converted to a value equal to the relative cell density of that control group.

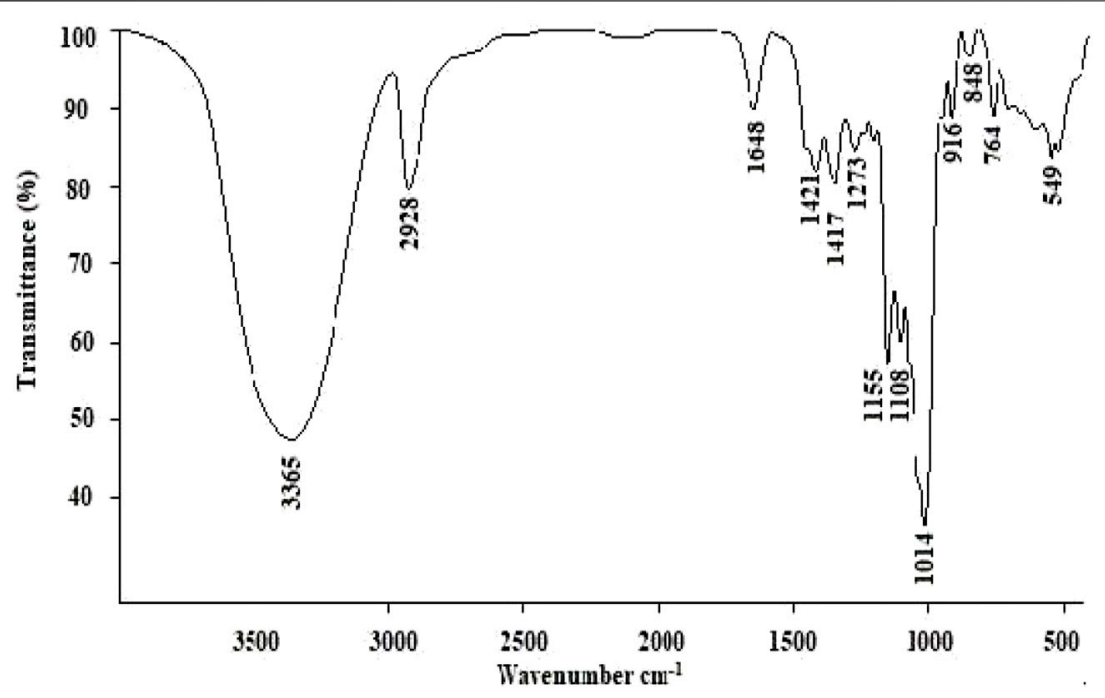

FIGURE 2 | FT-IR spectral analysis of LP4. 

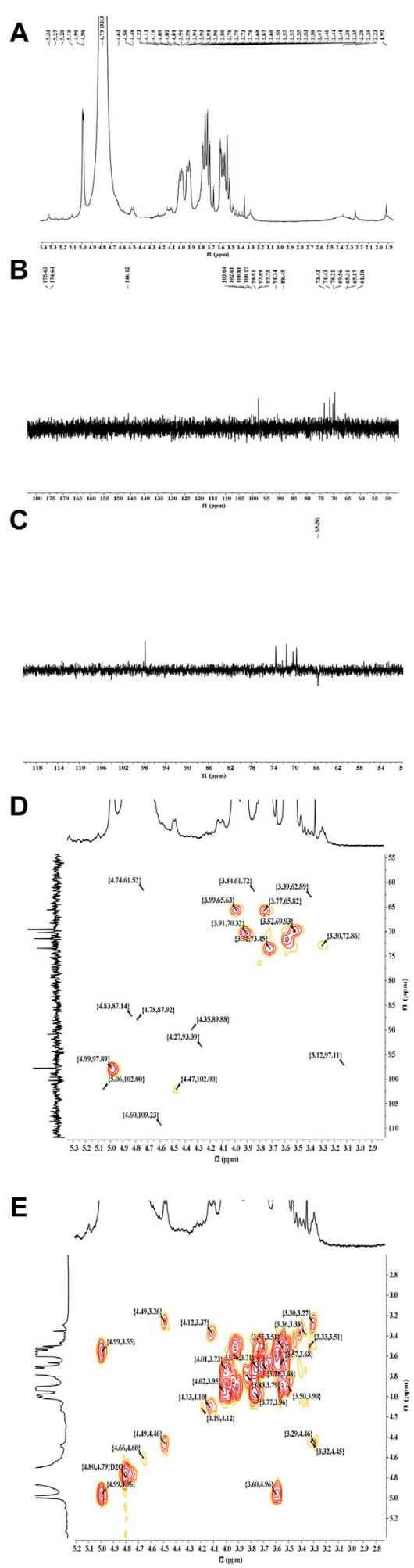

FIGURE 3 | The NMR spectra analysis of LP4. ${ }^{1} \mathrm{HNMR}$ (A), ${ }^{13} \mathrm{C}$ NMR (B), DEPT (C), HSQC (D), and COSY (E) spectra were recorded using an AV$400 \mathrm{MHz}$ spectrometer at $30^{\circ} \mathrm{C}$.

\section{Antibody Experiments}

Anti-TLR2, anti-TLR4 and anti-TLR2/4 (anti-TLR2 plus antiTLR4) were used to make sure the effect of TLR2 and TLR4 receptor in the LP4-induced macrophage activation. The cells were inoculated in 96-well plates and then treated with antiTLR2, anti-TLR4 and anti-TLR2/4 $(0.1 \mu \mathrm{g} / \mathrm{ml})$ for $30 \mathrm{~min}$. Then LP4 $(50 \mu \mathrm{g} / \mathrm{ml})$ was added for $24 \mathrm{~h}$. The supernatant was collected for analyzing the production of TNF- $\alpha$ and IL- $1 \beta$.

\section{Proliferation Assay of Splenic Lymphocytes}

The splenic lymphocytes were isolated according to the previous method (Jiang et al., 2014). The cells were inoculated into a 96well plate $\left(1 \times 10^{6}\right.$ cells $\left./ \mathrm{mL}\right)$ and cultured with $100 \mu \mathrm{L} /$ well RPMI1640 medium. Then LP4 $(12.5 \mu \mathrm{g} / \mathrm{ml} \sim 50 \mu \mathrm{g} / \mathrm{ml})$ with or without LPS $(10.0 \mu \mathrm{g} / \mathrm{ml})$ was added for $48 \mathrm{~h}$. Subsequently, $50 \mu \mathrm{L}$ MTT $(5 \mathrm{mg} / \mathrm{ml})$ was added and incubated for another $4 \mathrm{~h}$. Finally, the $100 \mu \mathrm{L}$ of acidified isopropyl alcohol was added. The optical density was measured at $570 \mathrm{~nm}$ with a microplate reader. The proliferation index of splenic lymphocytes was expressed as the percentage of the control group.

\section{Real-Time PCR Analysis}

LP4 $(25 \mu \mathrm{g} / \mathrm{ml})$ with or without anti-TLR2 and anti-TLR2/4 antibodies was added in RAW 264.7 cells. After incubated $4 \mathrm{~h}$, the total RNA was extracted from cells and cDNA was synthesized from $1 \mu \mathrm{g}$ of total RNA using a Reverse Transcription System kit (Thermo Fisher Scientific, Shanghai, China). The expression of INOS, PI3K, AKT, MyD88, TRAF6 and TRAF6 genes was assessed by real-time RT-PCR. Beta-actin was used as an internal control. The relative changes in expression of the target gene were derived using the CT $\left(2^{-\Delta \Delta C T}\right)$ method. The primers sequences used are presented in Supplementary Table $S 1$.

\section{Statistical Analysis}

The Data was expressed as an average of the replicates \pm standard deviation. SPSS statistic version 22.0 (SPSS. Inc., Chicago, IL) was used to perform statistical analysis of experimental results. A One-way analysis of variance (ANOVA) was used to evaluate the differences between the control and treatment groups. A $p$ value of $<0.05$ was considered as statistically significant.

\section{RESULTS}

\section{Molecular Parameters}

The high-performance liquid chromatography profiles of LP4 showed a single and symmetrical peak at $25.01 \mathrm{~min}$ (Figure 1A). Similarly, the result of SEC-MALLS (Figure 1B) showed a major peak at 23.26 min matched with RID signals.

The macromolecular characteristics parameters of LP4 are shown in Table 1. The Mw of LP4 was calculated as $6.31 \times 10^{4}(\mathrm{~g} / \mathrm{mol})$ and the $\mathrm{Mn}, \mathrm{Mz}$ and $\mathrm{Mp}$ were $3.58 \times 10^{4}(\mathrm{~g} / \mathrm{mol}), 2.25 \times 10^{5}(\mathrm{~g} / \mathrm{mol})$, and $2.87 \times 10^{4}(\mathrm{~g} / \mathrm{mol})$, respectively. The radius moments of LP4 were $56.32 \mathrm{~nm}(\mathrm{Rn}), 70.13 \mathrm{~nm}(\mathrm{Rw})$ and $100.65 \mathrm{~nm}(\mathrm{Rz})$. 


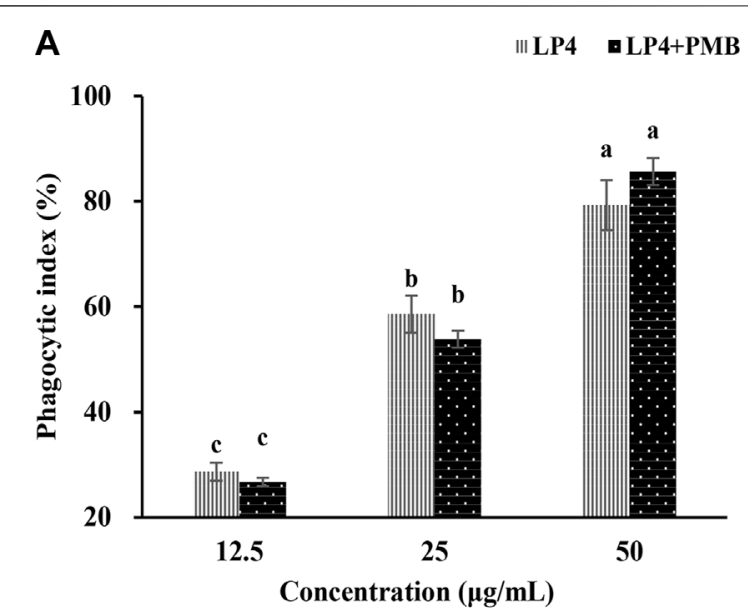

B
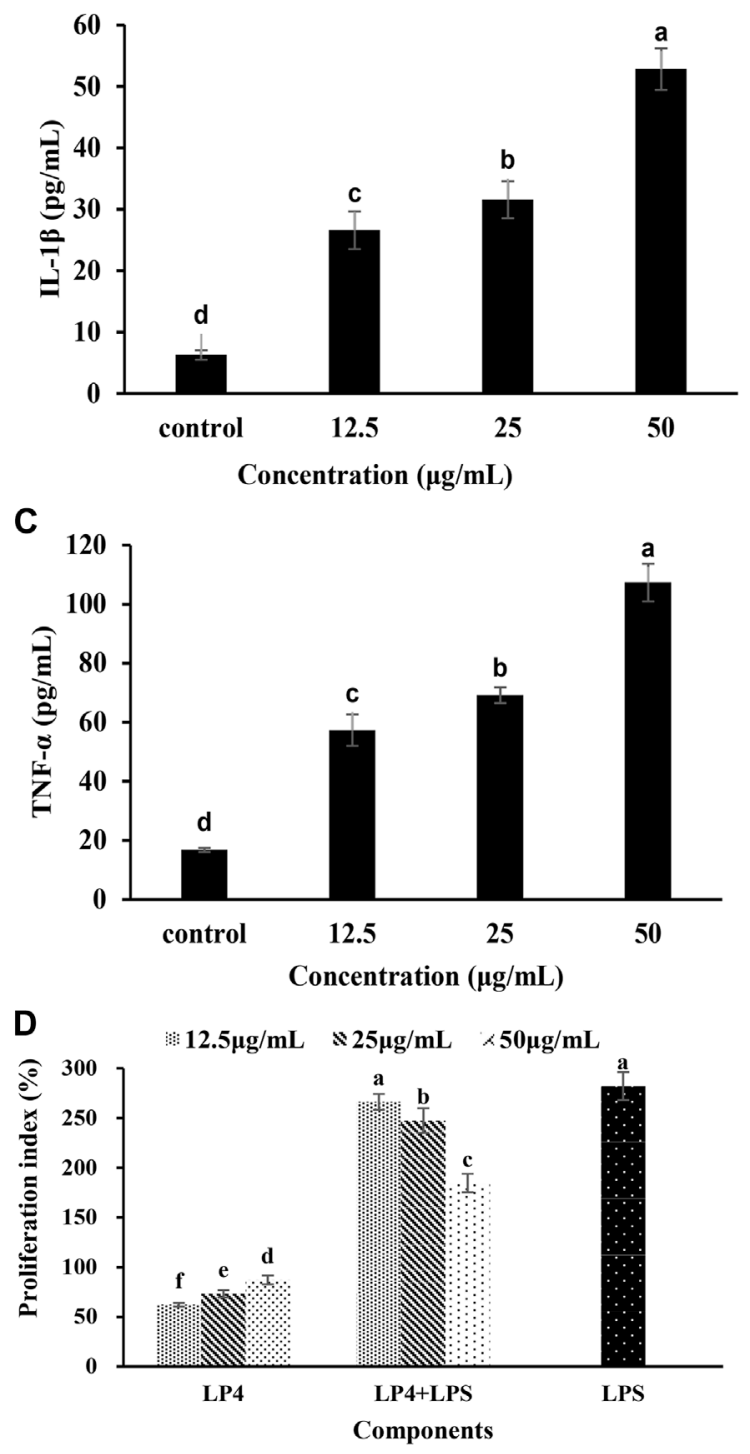

FIGURE 4 | Effects of LP4 to macrophages and the proliferation of splenic lymphocyte. Note: (A) Effects of LP4 $(12.550 \mu \mathrm{g} / \mathrm{mL})$ on

(Continued)
FIGURE 4| macrophages phagocytosis. (B) and (C) were the effects of LP4 on IL-1 $\beta$ and TNF- $\alpha$ secretion of macrophages, respectively. (D) Effects of LP4 on the proliferation of splenic lymphocyte. All data was expressed as means \pm standard deviation $(n=6)$. Different superscript letters above the bar are significantly different $(p<0.05)$.

\section{Monosaccharide Composition Analysis}

The monosaccharide composition analysis by GC chromatogram (Supplementary Figure S2) showed that LP4 was composed of mannose, glucose, glucuronic acid, galactose, xylose, arabinose, galacturonic acid, fucose, and rhamnose in a molar percentage of 36:31:10:7:4:4:3:2:2. The monosaccharide composition results indicated that LP4 was a hetero polysaccharide with high proportion of mannose (36.5 mol\%) and glucose (31.5 mol\%).

\section{Methylation Analysis}

To elucidate the glycosidic bonds configuration of LP4, methylation analysis was carried out. The results of GC/MS are summarized in Table 2. LP4 was mainly composed of $(1 \rightarrow 6)$ - $\operatorname{man} \quad(41.41 \mathrm{~mol} \%), \quad(1 \rightarrow 4)$-Glc $\quad(15.27 \mathrm{~mol} \%) \quad$ and $(1 \rightarrow 6)$-Glc $\quad(15.95 \mathrm{~mol} \%)$. Meanwhile, low percentage of $(1 \rightarrow 4)$-Gla $\quad(6.97 \mathrm{~mol} \%)$ and $(1 \rightarrow 4)$-Xyl $(4.36 \mathrm{~mol} \%)$ was detected in LP4.

\section{FT-IR Analysis}

As shown in Figure 2, the band at $3,365 \mathrm{~cm}^{-1}$ represented -OH stretching, and the band at $2,928 \mathrm{~cm}^{-1}$ was $-\mathrm{CH}$ stretching and bending vibrations ( $\mathrm{Xu}$ et al., 2016). The absorption bands at $1,648 \mathrm{~cm}^{-1}$ were identified as the stretching vibrations of $-\mathrm{C}=\mathrm{O}$ or -CHO. In addition, the band at $1,421 \mathrm{~cm}^{-1}$ indicated the presence of uronic acids (Wang et al., 2014). The band at $1,155 \mathrm{~cm}^{-1}$ was attributed to the stretching vibration of C-O (Yi et al., 2012). The absorption bands at $1,155 \mathrm{~cm}^{-1}$ and $1,014 \mathrm{~cm}^{-1}$ indicated a furanose form of sugar, which confirmed by the furanose characteristic band at $848 \mathrm{~cm}^{-1}$ (Ying et al., 2011).

\section{NMR Analysis}

Figure 3 shows the ${ }^{1} \mathrm{H}(\mathrm{A}),{ }^{13} \mathrm{C}(\mathrm{B})$, DEPT (C), HSQC (D) and COSY (E) spectrums of LP4. The chemical shifts at $\delta 3.20-\delta$ $5.50 \mathrm{ppm}$ in ${ }^{1} \mathrm{H}$ NMR spectrum were the signals of polysaccharide and the signals in $\delta 4.4-5.8 \mathrm{ppm}$ region represented the anomer of sugar residue (Song et al., 2019; Tian et al., 2020). Ordinarily, the signals at $\delta \quad 4.4-5.0 \mathrm{ppm}$ represent $\beta$-configuration and $\alpha$-configuration distributed in $\delta 5.0-5.8 \mathrm{ppm}$ (Liu et al., 2018). The HSQC spectrum (Figure 3D) showed the main anomeric signals with $\mathrm{H} 1 / \mathrm{C} 1$ values at $\delta 4.98 / \delta 97.89$. The proton signals of $\mathrm{H} 2, \mathrm{H} 3, \mathrm{H} 4, \mathrm{H} 5$, and $\mathrm{H} 6$ were acquired from the cross-peaks in $1 \mathrm{H}-1 \mathrm{H}$ COSY spectrum (Figure 3E) at $\delta 3.30,3.52,3.77,3.91$, and $3.99 \mathrm{ppm}$, respectively. The correlations between the proton and carbon signals, H2 $(\delta 3.30) / \mathrm{C} 2(\delta$ 72.86), H3 $(\delta 3.52) / \mathrm{C} 3(\delta$ 69.93), H4 ( $\delta 3.77) / \mathrm{C} 4(\delta 65.82), \mathrm{H} 5(\delta 3.91) / \mathrm{C} 5(\delta 70.32)$ and H6 $(\delta 3.99) / \mathrm{C} 6(\delta 65.63)$, could be assigned from the HSQC spectrum (Figure 3D). Combined with previous reports (Riccio et al., 1996; Song et al., 2019), the sugar residue was identified as $(1 \rightarrow 6)$ $\beta$-Man. Using a similar approach, the signals H1 $(\delta 4.99) / \mathrm{C} 1(\delta$ 97.75), H2 ( $\delta 3.58) / \mathrm{C} 2(\delta 71.16), \mathrm{H} 3(\delta 3.72) / \mathrm{C} 3(\delta 72.92), \mathrm{H} 4(\delta$ 

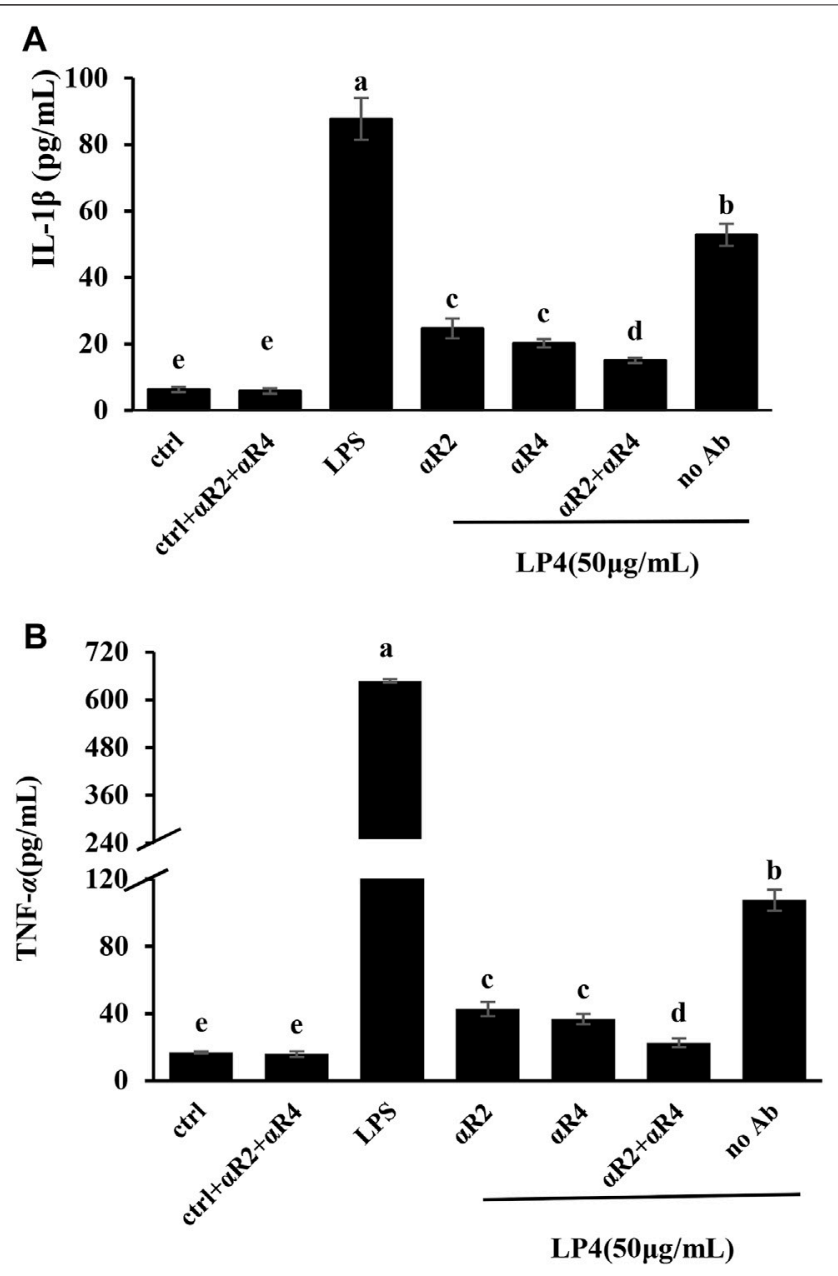

FIGURE 5 | Effects of anti-TLR2 and anti-TLR4 antibodies on LP4induced IL-1 $\beta$ and TNF- $\alpha$ secretion. RAW 264.7 cells were pre-treated with $0.1 \mu \mathrm{g} / \mathrm{ml}$ anti-TLR2 (aR2 group), anti-TLR4 (aR4 group), anti-TLR2 plus anti-TLR4 (aR2 + aR4 group, $0.1 \mu \mathrm{g} / \mathrm{ml}$ anti-TLR2 and $0.1 \mu \mathrm{g} / \mathrm{ml}$ anti-TLR4 antibodies) separately for $30 \mathrm{~min}$ before adding LP4 $(50 \mu \mathrm{g} / \mathrm{ml})$. The cells were pre-incubated with the medium (do not add antibodies) for $30 \mathrm{~min}$ and then LP4 (50 $\mu \mathrm{g} / \mathrm{ml})$, equal volume of medium or LPS $(10 \mu \mathrm{g} / \mathrm{ml})$ was added as the LP4 group (no Ab group), control group (ctrl group) and positive group (LPS group), respectively. After pre-treated with $0.1 \mu \mathrm{g} / \mathrm{ml}$ antiTLR2 plus $0.1 \mu \mathrm{g} / \mathrm{ml}$ anti-TLR4 for $30 \mathrm{~min}$, the cells were added the equal volume of medium as the antibodies control (ctrl $+\mathrm{aR} 2+\mathrm{aR} 4$ group). After 24 $\mathrm{h}, \mathrm{IL}-1 \beta$ (A) and TNF- $\alpha$ (B) in the culture supernatants were measured by ELISA. All data was expressed as means \pm standard deviation $(n=6)$. Different superscript letters above the bar are significantly different $(p<0.05)$.

$3.52) / \mathrm{C} 4(\delta 69.56), \mathrm{H} 5(\delta 3.91) / \mathrm{C} 5(\delta 69.79)$ and H6 $(\delta 3.77) / \mathrm{C} 6$ ( $\delta$ 65.29) was considered to be $(1 \rightarrow 6)$ - $\alpha$-glucose (Zhu et al., 2013; Luo et al., 2008; Cui et al., 2008). Moreover, the strong signal of C4 ( $\delta 69.56 \mathrm{ppm}$, Figure 3B) suggested that the high proportion of $(1 \rightarrow 4)$-linked glucose. The low signal at $4.47 /$ $102.00 \mathrm{ppm}(\mathrm{H} 1 / \mathrm{C} 1)$ in HSQC spectrum (Figure 3D) was attributed to $(1 \rightarrow 4)-\beta$-glucose (Yu et al., 2016). Others anomer signals ( $\delta 4.63,5.20,5.27$ and $5.33 \mathrm{ppm}$ ) were hard to confirm, due to relatively low response signals. It was clear that there was a small amount of galacturonic acid and glucuronic acid present in LP4 with the ${ }^{13} \mathrm{C}$ signals at $\delta$ 174-176 ppm (Marvelys et al., 2006; Ji et al., 2020). Combined with the results of monosaccharide composition, methylation and FT-IR, the backbone of LP4 was composed of $(1 \rightarrow 6)-\beta$-Man $(1 \rightarrow 4)-\beta$-Glc and $(1 \rightarrow 6)-\alpha$-Glc.

\section{Immunoregulatory Activity Analysis Phagocytosis of Macrophages Analysis}

As shown in Figure 4A, LP4 can promote the pinocytic activity of RAW264.7 cells and show a concentration-dependent at the concentration from 12.5 to $50 \mu \mathrm{g} / \mathrm{ml}$. When cells were treated with $50 \mu \mathrm{g} / \mathrm{ml} \mathrm{LP} 4$, the phagocytosis increased to $179.30 \%$. Moreover, when treatment macrophages with $\mathrm{PMB}$ $(1,000$ units $/ \mathrm{mL})$ plus LP4 $(12.5,25$ and $50 \mu \mathrm{g} / \mathrm{ml})$, the phagocytosis was no significant difference with the group treated with LP4 only, which indicated that LP4 was not contaminated by LPS. These results indicated that LP4 can activate the phagocytosis of macrophages.

\section{The Production of IL-1 $\beta$ and TNF- $\alpha$ Analysis}

As shown in Figure 4, the production of IL-1 $\beta$ (Figure 4B) and TNF- $\alpha$ (Figure 4C) were increased obviously and showed a concentration-dependent relationship, after treatment macrophages with LP4 $(12.5 \sim 50 \mu \mathrm{g} / \mathrm{ml})$. After treating macrophages with $50 \mu \mathrm{g} / \mathrm{ml}$ LP4, the IL- $1 \beta$ and TNF- $\alpha$ productions increased 8.39 times and 6.40 times, compared to the control group, respectively.

\section{Proliferation of Splenic Lymphocytes Analysis}

As shown in Figure 4D, LP4 significantly enhanced lymphocyte proliferation in a concentration-dependent manner $(12.5 \sim 50 \mu \mathrm{g} / \mathrm{ml}, p<0.05)$. Compared with control, $50 \mu \mathrm{g} / \mathrm{ml} \mathrm{LP} 4$ treatment increased the proliferation indices of splenic lymphocytes by $87.2 \%$. In combination with LPS, the splenic lymphocytes increased $266.4 \%(12.5 \mu \mathrm{g} / \mathrm{ml} \mathrm{LP} 4), 247.5 \%(25 \mu \mathrm{g} / \mathrm{ml}$ LP4) and $184.6 \%(50 \mu \mathrm{g} / \mathrm{ml} \mathrm{LP} 4)$ of the control value. The proliferation indices of the LP4 plus LPS groups were significantly higher than that of LP4 groups but lower than that of LPS group. The result might due to LP4 and LPS competing for common receptors present on the cell surface. Consistent with activation of macrophages, these results suggested that LP4 activate the immune system.

\section{Membrane Receptor Analysis}

To confirm the membrane receptors involved in LP4induced macrophage activation, the macrophages were preprocessed by anti-TLR2, anti-TLR4 and anti-TLR2/4. As shown in Figure 5, contrasting with the group treated with LP4 only (No Ab group), the levels of TNF- $\alpha$ and IL-1 $\beta$ were significantly suppressed after treating with anti-TLR2, anti-TLR4 and anti-TLR2/4 $(p<0.05)$. There were no significant differences between treatment with anti-TLR2 and anti-TLR4 $(p>0.05)$. IL-1 $\beta$ and TNF- $\alpha$ were 28.34 and $21.05 \%$ after treating with anti-TLR2/4, compared with the group treated with LP4 only, respectively. Moreover, the group with anti-TLR2/TLR4 but without LP4 (ctrl + aTLR2 + aTLR4 group) did not shown difference from the control group (ctrl group). These 


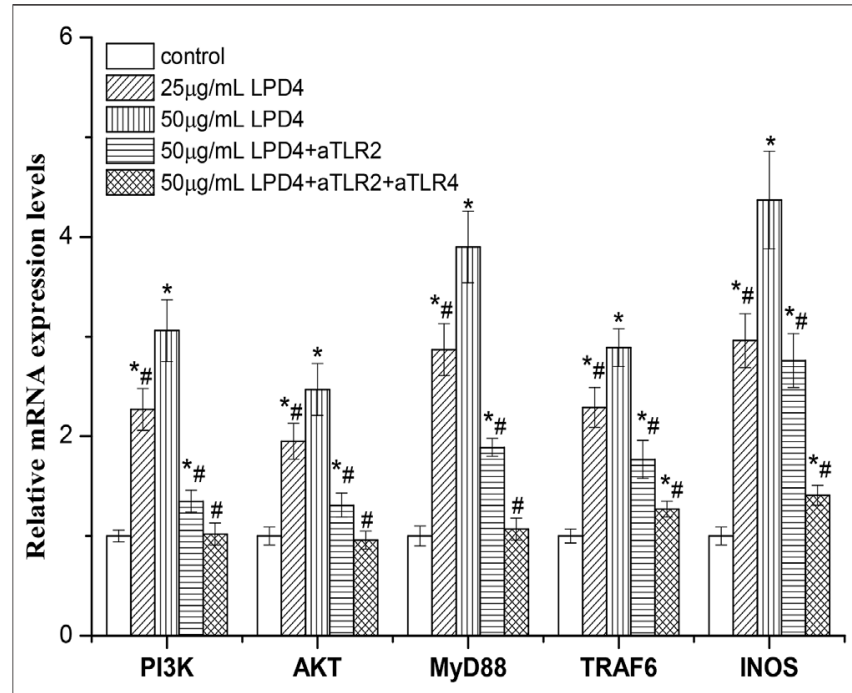

FIGURE 6|Effect of LP4 on the gene expressions of PI3K, AKT, MyD88, TRAF6, and INOS of macrophage. After RAW 264.7 cells were pre-treated with or without anti-TLR2 $(0.1 \mu \mathrm{g} / \mathrm{ml})$ or anti-TLR2 plus anti-TLR4 $(0.1 \mu \mathrm{g} / \mathrm{ml}$ anti-TLR2 and $0.1 \mu \mathrm{g} / \mathrm{ml}$ anti-TLR4) antibodies, the cells were incubated with LP4 $(25 \mu \mathrm{g} / \mathrm{ml}$ and $50 \mu \mathrm{g} / \mathrm{ml})$ for $4 \mathrm{~h}(n=4)$. The mRNA expression levels detected by RT-PCR were relative to that of the reference gene, $\beta$-actin. ${ }^{\star} p<0.05$ compared with the control group; \# $p<0.05$ compared with the $50 \mu \mathrm{g} / \mathrm{ml}$ LP4 group.

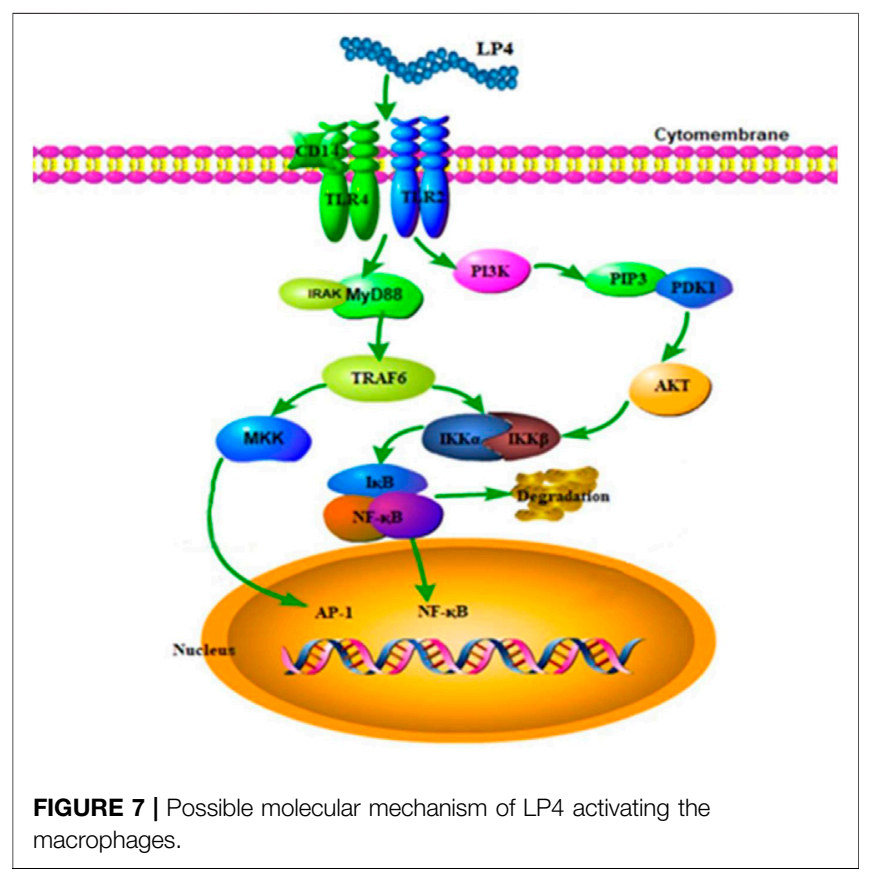

results suggest that LP4 induce macrophage activation mainly via TLR2 and TLR4 receptor.

\section{Regulatory Pathways Analysis}

As shown in Figure 6, LP4 $(12.5 \sim 50 \mu \mathrm{g} / \mathrm{ml})$ up-regulated the expression of INOS, PI3K, AKT, MyD88, and TRAF6 mRNA of macrophage, in a concentration-dependent manner.
When treated with $50 \mu \mathrm{g} / \mathrm{ml} \mathrm{LP} 4$, the expression levels of INOS, PI3K, AKT, MyD88, and TRAF6 were $4.37 \pm 0.28$, $3.06 \pm 0.19,2.47 \pm 017,3.90 \pm 0.24$, and $2.89 \pm 0.16$ times as many as the control group, respectively. Moreover, the expression of these genes was obviously decreased when treated with anti-TLR2 and anti-TLR2/4. The expression levels of INOS, PI3K, AKT, MyD88, and TRAF6 were reduced to $2.76 \pm 0.20,1.35 \pm 0.11,1.31 \pm 0.09,1.89 \pm$ 0.14 , and $1.77 \pm 0.09$ times (compare with control group) after treatment with anti-TLR2. Meanwhile, the expression levels of these genes decreased to $1.41 \pm 0.11,1.02 \pm 0.06$, $0.96 \pm 0.08,1.07 \pm 0.05$, and $1.20 \pm 0.07$ of the control group after treatment with anti-TLR2/4, respectively. These results indicate that TLR2 and TLR4-mediated PI3K/AKT and MyD88/TRAF6 pathways involved in the activation of LP4 to macrophages.

\section{DISCUSSION}

The characterization of main active components, active mechanism, and structure-function relationship are the basis of the function and application of natural products. In recent years, several active polysaccharides were used as therapeutic agent for treatment disease (Yu et al., 2018). However, the application of many polysaccharides from natural sources was limited due to the complex structure and unclear structure-activity relationship (Harding et al., 2017). In the present study, a novel active polysaccharide of longan (LP4), which main linkages were $(1 \rightarrow 6)-\beta$-Man $(1 \rightarrow 4)-\beta$-Glc and $(1 \rightarrow 6)-\alpha$-Glc with average molecular weight of $6.31 \times 10^{4} \mathrm{~g} / \mathrm{mol}$, was characterized and its immunomodulation activities were evaluated. The structure and macrophage-activating mechanism of LP4 are dramatically different from longan polysaccharides in previous reports (Yi et al., 2011; Meng et al., 2014; Rong et al., 2019). The comparative analysis of structures and activities may help reveal the structure-function relationships and uncover the multiple molecular mechanism of activating macrophages of longan polysaccharides. Previous studies demonstrated that the bioactivity of polysaccharide was closely associated with their structural features (Ferreira et al., 2015). The $(1 \rightarrow 4)$-Glc $(1 \rightarrow 6)$-Glc, and $(1 \rightarrow 6)$-Man were found to be the main backbone for many polysaccharides with immunomodulatory activity (Ferreira et al., 2015; Yamabhai et al., 2016; Yan et al., 2018), including longan polysaccharides (Rong et al., 2019; Gan et al., 2021). The linkage characteristics of $(1 \rightarrow 4)$-Glc $(1 \rightarrow 6)$-Glc and $(1 \rightarrow 6)$-Man may contribute to immunoregulatory activity of LP4. In previous studies, it has been proposed that polysaccharides with considerable activities normally have high molecular weight and acetyl or sulfuric acid functional groups (Ferreira et al., 2015; Rong et al., 2019). However, the current study results show that the high molecular weight and acetyl or sulfuric acid functional groups are not the necessarily structural features of longan polysaccharide with strong immunoregulatory activity. LP4 has a 
relatively lower molecular weight $\left(6.31 \times 10^{4} \mathrm{~g} / \mathrm{mol}\right)$ and no acetyl or sulfuric acid groups, while it showed strong immunoregulatory activity.

Polysaccharide mediated immune regulation is a complex process. The triggering of cellular immune response by polysaccharides mainly depends on pattern recognition receptors on immune cells (Leung et al., 2006). Toll-like receptors play an important role in polysaccharides induced macrophage activation. Meanwhile, the PI3K/AKT and MyD88 pathways play a key role in the TLR2-and TLR4-mediated activation of macrophages, respectively (Feng et al., 2016; Vergadi et al., 2017). Previous studies showed that several polysaccharides from natural sources activated macrophage through TLR2 and TLR4-mediated MAPK/NF-kappa B (Wang et al., 2018a; Yang et al., 2019) and transcriptional activities of activator protein-1 (Shen et al., 2017). In this study, we found that LP4 induced activation of macrophages via TLR2 and TLR4 mediated with PI3K/AKT and MyD88/ TRAF6 pathways. In our early study, the dried longan pulp polysaccharide LPD2 with $(1 \rightarrow 4)-\beta$-Glc and $(1 \rightarrow 6)-\beta$-Man glycosidic linkages was not shown to activate macrophages via TLR2-mediated PI3K/AKT pathway (Rong et al., 2019). The difference in the structure of the two polysaccharides may lead to the difference in the signal pathway of macrophages activation. There are differences in the mechanism of activating macrophages by longan polysaccharide with different structures. In the present study, the expression of INOS and TRAF6 induced by LP4 was not completely suppressed by anti-TLR2/4. These results suggested that there may be other signal pathways or receptors involved in LP4-mediated macrophage activation. In summary, LP4 induced the activation of macrophage mainly via the TLR2 and TLR4-induced PI3K/AKT and MyD88/TRAF6 pathways (Figure 7).

\section{CONCLUSION}

In this work, a novel immunoreactive polysaccharide with average molecular weight of $6.31 \times 10^{4} \mathrm{~g} / \mathrm{mol}$ was isolated from fresh longan. It was composed of mannose, glucose, glucuronic acid, galactose, xylose, arabinose, galacturonic acid, fucose, and rhamnose in a molar percentage of $36: 31$ : 10:7:4:4:3:2:2 and mainly linked by $(1 \rightarrow 6)-\beta$-Man, $(1 \rightarrow 4)$ $\beta$-Glc, and $(1 \rightarrow 6)-\alpha$-Glc. LP4 can promote the proliferation

\section{REFERENCES}

Bai, Y., Jia, X., Huang, F., Zhang, R., Dong, L., Liu, L., et al. (2020). Structural Elucidation, Anti-Inflammatory Activity and Intestinal Barrier protection of Longan Pulp Polysaccharide LPIIa. Carbohydr. Polym. 246, 116532. doi:10.1016/j.carbpol.2020.116532

Cui, H., Liu, Q., Tao, Y., Zhang, H., Zhang, L., and Ding, K. (2008). Structure and Chain Conformation of a $(1 \rightarrow 6)-\alpha-D-G l u c a n$ from the Root of Pueraria Lobata (Willd.) Ohwi and the Antioxidant Activity of its Sulfated Derivative. Carbohydr. Polym. 74 (4), 771-778. doi:10.1016/j.carbpol.2008.04.034 of lymphocytes and enhanced the phagocytosis of macrophage. Moreover, LP4 induced the activation of macrophage mainly via the TLR2 and TLR4-mediated PI3K/AKT and MyD88/TRAF6 pathways.

\section{DATA AVAILABILITY STATEMENT}

The raw data supporting the conclusions of this article will be made available by the authors, without undue reservation.

\section{ETHICS STATEMENT}

The animal study was reviewed and approved by the Institutional Animal Care and Use committee of South China Agricultural University.

\section{AUTHOR CONTRIBUTIONS}

Methodology, WL and RY; methodology, HL and JX; formal analysis, $\mathrm{YY}$ and $\mathrm{ZT}$; investigation, $\mathrm{HL}$ and $\mathrm{YY}$; resources, WL and RY; data curation, HL and YY; writing - original draft preparation, HL and WL; writing - review and editing, WL and RY; validation, YY and JX; funding acquisition, WL and RY. All authors contributed to manuscript revision, read, and approved the submitted version.

\section{FUNDING}

This work was financially supported by the Natural Science Foundation of China (31960481; 31360380), the Natural Science Foundation of Guangdong Province, China (2021A1515012135), and the State Key Research and Development Plan "modern food processing and food storage and transportation technology and equipment" (2017YFD 0400200).

\section{SUPPLEMENTARY MATERIAL}

The Supplementary Material for this article can be found online at: https://www.frontiersin.org/articles/10.3389/fphar.2021.786127/ full\#supplementary-material

Feng, Z., Wang, Z., Yang, M., Zhou, L., and Bao, Y. (2016). Polysaccharopeptide Exerts Immunoregulatory Effects via MyD88-Dependent Signaling Pathway. Int. J. Biol. Macromol. 82, 201-207. doi:10.1016/j.ijbiomac.2015.11.002

Ferreira, S. S., Passos, C. P., Madureira, P., Vilanova, M., and Coimbra, M. A. (2015). Structure-Function Relationships of Immunostimulatory Polysaccharides: A Review. Carbohydr. Polym. 132, 378-396. doi:10.1016/ j.carbpol.2015.05.079

Gan, T., Feng, C., Lan, H., Yang, R., Zhang, J., Li, C., et al. (2021). Comparison of the Structure and Immunomodulatory Activity of Polysaccharides from Fresh and Dried Longan. J. Funct. Foods 76, 104323. doi:10.1016/ j.jff.2020.104323 
Harding, S. E., Tombs, M. P., Adams, G. G., Paulsen, B. S., Inngjerdingen, K. T., and Barsett, H. (2017). An Introduction to Polysaccharide Biotechnology. Boca Raton, Florida: CRC Press.

He, X., Fang, J., Guo, Q., Wang, M., Li, Y., Meng, Y., et al. (2020). Advances in Antiviral Polysaccharides Derived from Edible and Medicinal Plants and Mushrooms. Carbohydr. Polym. 229, 115548. doi:10.1016/ j.carbpol.2019.115548

Ji, X., Yan, Y., Hou, C., Shi, M., and Liu, Y. (2020). Structural Characterization of a Galacturonic Acid-Rich Polysaccharide from Ziziphus Jujuba Cv. Muzao. Int. J. Biol. Macromol 147, 844-852. doi:10.1016/j.ijbiomac.2019.09.244

Jiang, J., Meng, F. Y., He, Z., Ning, Y. L., Li, X. H., Song, H., et al. (2014). Sulfated Modification of Longan Polysaccharide and its Immunomodulatory and Antitumor Activity In Vitro. Int. J. Biol. Macromol. 67, 323-329. doi:10.1016/j.ijbiomac.2014.03.030

Leung, M. Y., Liu, C., Koon, J. C., and Fung, K. P. (2006). Polysaccharide Biological Response Modifiers. Immunol. Lett. 105 (2), 101-114. doi:10.1016/ j.imlet.2006.01.009

Lin, Z., and Sun, L. (2019). Antitumor Effect of Ganoderma (Lingzhi) Mediated by Immunological Mechanism and its Clinical Application. Ganoderma and Health 1182, 39-77. doi:10.1007/978-981-32-9421-9_2

Liu, W., Lv, X., Huang, W., Yao, W., and Gao, X. (2018). Characterization and Hypoglycemic Effect of a Neutral Polysaccharide Extracted from the Residue of Codonopsis Pilosula. Carbohydr. Polym. 197, 215-226. doi:10.1016/ j.carbpol.2018.05.067

López-Legarda, X., Arboleda-Echavarría, C., Parra-Saldívar, R., Rostro-Alanis, M., Alzate, J. F., Villa-Pulgarín, J. A., et al. (2020). Biotechnological Production, Characterization and In Vitro Antitumor Activity of Polysaccharides from a Native Strain of Lentinus Crinitus. Int. J. Biol. Macromolint. J. Biol. Macromol. 164, 3133-3144. doi:10.1016/j.ijbiomac.2020.08.191

Long, F., Wang, Y. X., Liu, L., Zhou, J., Cui, R. Y., and Jiang, C. L. (2005). Rapid Nongenomic Inhibitory Effects of Glucocorticoids on Phagocytosis and Superoxide Anion Production by Macrophages. Steroids 70 (1), 55-61. doi:10.1016/j.steroids.2004.10.004

Luo, X., Xu, X., Yu, M., Yang, Z., and Zheng, L. (2008). Characterisation and Immunostimulatory Activity of an $\alpha$-( $1 \rightarrow 6)$-d-Glucan from the Cultured Armillariella Tabescens Mycelia. Food Chem. 111 (2), 357-363. doi:10.1111/ omi.1227210.1016/j.foodchem.2008.03.076

Marvelys, L., Maritza, M., Lilian, S., de Pinto Gladys, L., and Julio, H. (2006). Structural Elucidation of the Polysaccharide from Sterculia Apetala Gum by a Combination of Chemical Methods and NMR Spectroscopy. Food Hydrocolloids 20 (6), 908-913. doi:10.1016/ j.foodhyd.2005.09.005

Masuko, T., Minami, A., Iwasaki, N., Majima, T., Nishimura, S., and Lee, Y. C. (2005). Carbohydrate Analysis by a Phenol-Sulfuric Acid Method in Microplate Format. Anal. Biochem. 339 (1), 69-72. doi:10.1016/j.ab.2004.12.001

Meng, F. Y., Ning, Y. L., Qi, J., He, Z., Jie, J., Lin, J. J., et al. (2014). Structure and Antitumor and Immunomodulatory Activities of a Water-Soluble Polysaccharide from Dimocarpus Longan Pulp. Int. J. Mol. Sci. 15 (3), 5140-5162. doi:10.3390/ijms15035140

Needs, P. W., and Selvendran, R. R. (1993). Avoiding Oxidative Degradation during Sodium Hydroxide/Methyl Iodide-Mediated Carbohydrate Methylation in Dimethyl Sulfoxide. Carbohydr. Res. 245 (1), 1-10. doi:10.1016/00086215(93)80055-J

Riccio, R., Kinnel, R. B., Bifulco, G., and Scheuer, P. J. (1996). Kakelokelose, a Sulfated Mannose Polysaccharide with Anti-HIV Activity from the Pacific Tunicate Didemnum Molle. Tetrahedron Lett. 37 (12), 1979-1982. doi:10.1016/ 0040-4039(96)00262-6

Rong, Y., Yang, R., Yang, Y., Wen, Y., Liu, S., Li, C., et al. (2019). Structural Characterization of an Active Polysaccharide of Longan and Evaluation of Immunological Activity. Carbohydr. Polym. 213, 247-256. doi:10.1016/ j.carbpol.2019.03.007

Shen, T., Wang, G., You, L., Zhang, L., Ren, H., Hu, W., et al. (2017). Polysaccharide from Wheat Bran Induces Cytokine Expression via the TollLike Receptor 4-mediated P38 MAPK Signaling Pathway and Prevents Cyclophosphamide-Induced Immunosuppression in Mice. Food Nutr. Res. 61 (1), 1344523. doi:10.1080/16546628.2017.1344523
Song, Y., Zhu, M., Hao, H., Deng, J., Li, M., Sun, Y., et al. (2019). Structure Characterization of a Novel Polysaccharide from Chinese Wild Fruits (Passiflora Foetida) and its Immune-Enhancing Activity. Int. J. Biol. Macromol. 136, 324-331. doi:10.1016/j.ijbiomac.2019.06.090

Tian, W., Xiao, N., Yang, Y., Xiao, J., Zeng, R., Xie, L., et al. (2020). Structure, Antioxidant and Immunomodulatory Activity of a Polysaccharide Extracted from Sacha Inchi Seeds. Int. J. Biol. Macromol. 162, 116-126. doi:10.1016/ j.ijbiomac.2020.06.150

Vergadi, E., Ieronymaki, E., Lyroni, K., Vaporidi, K., and Tsatsanis, C. (2017). Akt Signaling Pathway in Macrophage Activation and M1/M2 Polarization. J. Immunol. 198 (3), 1006-1014. doi:10.4049/jimmunol.1601515

Wang, Z. B., Pei, J. J., Ma, H. L., Cai, P. F., and Yan, J. K. (2014). Effect of Extraction media on Preliminary Characterizations and Antioxidant Activities of Phellinus Linteus Polysaccharides. Carbohydr. Polym. 109, 49-55. doi:10.1016/ j.carbpol.2014.03.057

Wang, X., Zhang, L., Wu, J., Xu, W., Wang, X., and Lü, X. (2017). Improvement of Simultaneous Determination of Neutral Monosaccharides and Uronic Acids by Gas Chromatography. Food Chem. 220, 198-207. doi:10.1016/ j.foodchem.2016.10.008

Wang, D. D., Pan, W. J., Mehmood, S., Cheng, X. D., and Chen, Y. (2018a). Polysaccharide Isolated from Sarcodon Aspratus Induces RAW264.7 Activity via TLR4-Mediated NF-Kb and MAPK Signaling Pathways. Int. J. Biol. Macromol. 120, 1039-1047. doi:10.1016/j.ijbiomac.2018.08.147

Wang, Z., Xie, J., Shen, M., Nie, S., and Xie, M. (2018b). Sulfated Modification of Polysaccharides: Synthesis, Characterization and Bioactivities. Trends Food Sci. Technol. 74, 147-157. doi:10.1016/j.tifs.2018.02.010

Weeks, B. A., Keisler, A. S., Myrvik, Q. N., and Warinner, J. E. (1987). Differential Uptake of Neutral Red by Macrophages from Three Species of Estuarine Fish. Dev. Comp. Immunol. 11 (1), 117-124. doi:10.1016/ 0145-305X(87)90013-9

Xie, J. H., Jin, M. L., Morris, G. A., Zha, X. Q., Chen, H. Q., Yi, Y., et al. (2016). Advances on Bioactive Polysaccharides from Medicinal Plants. Crit. Rev. Food Sci. Nutr. 56 (Suppl. 1), S60-S84. doi:10.1080/ 10408398.2015.1069255

Xu, Y., Liu, G., Yu, Z., Song, X., Li, X., Yang, Y., et al. (2016). Purification, Characterization and Antiglycation Activity of a Novel Polysaccharide from Black Currant. Food Chem. 199, 694-701. doi:10.1016/ j.foodchem.2015.12.078

Yamabhai, M., Sak-Ubol, S., Srila, W., and Haltrich, D. (2016). Mannan Biotechnology: from Biofuels to Health. Crit. Rev. Biotechnol. 36 (1), 32-42. doi:10.3109/07388551.2014.923372

Yan, J., Han, Z., Qu, Y., Yao, C., Shen, D., Tai, G., et al. (2018). Structure Elucidation and Immunomodulatory Activity of a $\beta$-Glucan Derived from the Fruiting Bodies of Amillariella Mellea. Food Chem. 240, 534-543. doi:10.1016/j.foodchem.2017.07.154

Yang, B., Jiang, Y., Shi, J., Chen, F., and Ashraf, M. (2011). Extraction and Pharmacological Properties of Bioactive Compounds from Longan (Dimocarpus Longan Lour.) Fruit - A Review. Food Res. Int. 44 (7), 1837-1842. doi:10.1016/j.foodres.2010.10.019

Yang, F., Li, X., Yang, Y., Ayivi-Tosuh, S. M., Wang, F., Li, H., et al. (2019). A Polysaccharide Isolated from the Fruits of Physalis Alkekengi L. Induces RAW264.7 Macrophages Activation via TLR2 and TLR4-Mediated MAPK and NF-Kb Signaling Pathways. Int. J. Biol. Macromol. 140, 895-906. doi:10.1016/j.ijbiomac.2019.08.174

Yi, Y., Zhang, M.-W., Liao, S.-T., Zhang, R.-F., Deng, Y.-Y., Wei, Z.-C., et al. (2012). Structural Features and Immunomodulatory Activities of Polysaccharides of Longan Pulp. Carbohydr. Polym. 87 (1), 636-643. doi:10.1016/j.carbpol.2011.08.034

Yi, Y., Wang, H., Zhang, R., Min, T., Huang, F., Liu, L., et al. (2015). Characterization of Polysaccharide from Longan Pulp as the Macrophage Stimulator. RSC Adv. 5 (118), 97163-97170. doi:10.1039/C5RA16044H

Ying, Z., Han, X., and Li, J. (2011). Ultrasound-Assisted Extraction of Polysaccharides from Mulberry Leaves. Food Chem. 127 (3), 1273-1279. doi:10.1016/j.foodchem.2011.01.083

Yu, L., Xu, S., Deng, C., Li, H., Yang, Q., Xu, Z., et al. (2016). Preparation and Partial Structural Characterization of the Exopolysaccharide from Bacillus Mucilaginosus SM-01. Carbohydr. Polym. 146, 217-223. doi:10.1016/ j.carbpol.2016.03.038 
Yu, Y., Shen, M., Song, Q., and Xie, J. (2018). Biological Activities and Pharmaceutical Applications of Polysaccharide from Natural Resources: A Review. Carbohydr. Polym. 183, 91-101. doi:10.1016/j.carbpol.2017.12.009

Zhang, J., Yang, G., Wen, Y., Liu, S., Li, C., Yang, R., et al. (2017). Intestinal Microbiota Are Involved in the Immunomodulatory Activities of Longan Polysaccharide. Mol. Nutr. Food Res. 61 (11), 1700466. doi:10.1002/mnfr.201700466

Zhu, Q., Jiang, Y., Lin, S., Wen, L., Wu, D., Zhao, M., et al. (2013). Structural Identification of $(1 \rightarrow 6)-\alpha-D-G l u c a n, a$ Key Responsible for the Health Benefits of Longan, and Evaluation of Anticancer Activity. Biomacromolecules 14 (6), 1999-2003. doi:10.1021/bm400349y

Conflict of Interest: The authors declare that the research was conducted in the absence of any commercial or financial relationships that could be construed as a potential conflict of interest.
Publisher's Note: All claims expressed in this article are solely those of the authors and do not necessarily represent those of their affiliated organizations, or those of the publisher, the editors and the reviewers. Any product that may be evaluated in this article, orclaim that may be made by its manufacturer, is not guaranteed or endorsed by the publisher.

Copyright (c) $2021 \mathrm{Lan}, \mathrm{Li}, \mathrm{Xu}$, Yang, Tan and Yang. This is an open-access article distributed under the terms of the Creative Commons Attribution License (CC BY). The use, distribution or reproduction in other forums is permitted, provided the original author(s) and the copyright owner(s) are credited and that the original publication in this journal is cited, in accordance with accepted academic practice. No use, distribution or reproduction is permitted which does not comply with these terms. 